\title{
ON WILKER-TYPE INEQUALITIES
}

\author{
LING ZHU
}

Abstract. In this note, two Wilker-type inequalities involving hyperbolic functions are established.

Mathematics subject classification (2000): 26D05, $26 \mathrm{D} 15$.

Key words and phrases: Wilker-type inequalities, hyperbolic functions.

\section{REFERENCES}

[1] J. B. WILKER, E3306, The American Mathematical Monthly, 96, (1989), 1-55.

[2] J. S. SUMNER, A. A. JAGERS, M. VOWE AND J. ANGLESIO, Inequalities involving trigonometric functions, The American Mathematical Monthly, 98, (3) (1991), 264-267.

[3] B. N. GuO, B. M. QIAO, F. QI AND W. LI, On new proofs of Wilker's inequalities involving trigonometric functions, Mathematical Inequalities \& Applications, 6, (1) (2003), 19-22.

[4] L. ZHU, A new simple proof of Wilker's inequality, Mathematical Inequalities \& Applications, 8, (4) (2005), 749-750.

[5] I. PINELIS, L'Hospital rules for monotonicity and the Wilker-Anglesio Inequality, The American Mathematical Monthly, 111, (2004), 905-909.

[6] L. ZHANG, L. ZHU, A new elementary proof of Wilker's inequalities, Mathematical Inequalities \& Applications, to appear.

[7] G. D. Anderson, M. K. Vamanamurthy and M. Vuorinen, Conformal invariants, inequalities and quasiconformal maps, New York, 1997.

[8] G. D. Anderson, S.-L. Qiu, M. K. Vamanamurthy and M. Vuorinen, Generalized elliptic integral and modular equations, Pacific J.Math., 192, (2000), 1-37.

[9] H. AlzER, S.-L. QIU, Inequalities for means in two variables, Arch. Math., 80, (2003), 201-215.

[10] S. PonnusAmy, M. VuORINEN, Asymptotic expansions and inequalities for hypergeometric functions, Mathematika, 44, (1997), 278-301.

[11] H. AlZER, S.-L. QIU, Monotonicity theorems and inequalities for the complete elliptic integrals, J. Comp. Appl. Math., 172, (2004), 289-312.

[12] D. S. MitRINOVIC, Analytic inequalities, Springer-Verlag, 1970. 